\title{
O PROCESSO PENAL CONSTITUCIONAL E O DEVIDO PROCESSO LEGAL COMO GARANTIA DEMOCRÁTICA
}

\author{
THE CRIMINAL PROCEDURE CONSTITUTIONAL \\ AND LEGAL DUE PROCESS AS GUARANTEED \\ DEMOCRATIC
}

\author{
Fábio Passos Presoti \\ José de Assis Santiago Neto
}

\section{RESUMO}

O Estado Democrático de Direito é o resultado, ainda em construção, de um processo de evolução da sociedade que, desde o rompimento com o antigo regime absolutista vem se construindo na constante busca para a tutela dos direitos do ser humano. Assim, o presente artigo, partindo de uma premissa do referido modelo, tem como objetivo analisar seus reflexos no processo penal, tendo como ponto de apoio a teoria do processo constitucional. A democracia exige uma participação discursiva que somente será obtida pelo processo em que as decisões serão legitimadas pela ampla participação democrática daqueles que sofrerão os efeitos da decisão. Assim, o processo penal democrático deve ter como pressuposto básico o princípio constitucional da não culpabilidade e pelo sistema acusatório, devendo o papel dos envolvidos no processo ser revisto e, sobretudo, o do julgador, uma vez que tem em mãos o poder de produzir e gerir as provas do procedimento.

Palavras-chave: Processo penal. Jurisdição. Partes. Democracia. Participação. Discursividade. 


\section{ABSTRACT}

The Rule of Law is the result, still under construction, a process of evolution of society that since the break with the old absolutist regime has been building in the constant search for the protection of human rights. Thus, this article seeks, starting from a premise of that model, analyze its consequences in criminal proceedings, having as support the theory of the constitutional process. Democracy requires participation discourse that can only be achieved by the process, where decisions are legitimized through the broad democratic participation of those who suffer the effects of the decision. Thus, the prosecution should have democracy as a basic premise the constitutional principle of not guilty and the adversarial system, and the role of those involved in the process be reviewed and, above all, the judge, as he has in his hands the power to produce and manage the evidence procedure.

Keywords: Criminal proceedings. Jurisdiction. Parties. Democracy. Participation. Discourse.

\section{INTRODUÇÃO}

A participação da sociedade no espaço público é a marca característica do Estado Democrático de Direito na visão de Habermas. Tal fenômeno não pode, e nem deve fugir aos olhos do Direito Processual, que deve servir como meio de se assegurar a devida participação dos sujeitos, que serão afetados diretamente pelo provimento na construção da decisão.

O processo penal também não foge à regra, devendo garantir às partes, Ministério Público (ou querelante em casos de ação penal privada) e defesa (acusado e defesa técnica) a participação em paridade de armas na construção do provimento jurisdicional penal. São as regras da democracia que exigem tal comportamento.

Servirá de base teórica a teoria constitucionalista do processo, pois atualmente o processo apresenta-se como instituição constitucionalizada que possui principiologia constitucional do devido processo constitucional, convertendo-se como direito-garantia, uma vez que o processo constitucional não é somente um direito instrumental, mas verdadeira metodologia de garantia dos direitos fundamentais. Pelo processo constitucional, o direito de ação e o de defesa são assegurados 
de forma completa a todos os indivíduos, devendo o processo ser justo e leal. ${ }^{3}$ Dizer que o processo deve ser justo significa que deve ser organizado segundo as regras que respeitem as garantias fundamentais, primordialmente o contraditório. ${ }^{4}$

A teoria da relação jurídica, que deu origem à concepção instrumentalista do processo e, ainda hoje, tem adeptos de renome no Brasil, insere o juiz em posição de supremacia em relação aos demais sujeitos do processo. Fazzalari rompeu com a teoria da relação jurídica, porém não o fez de forma constitucionalizada, o que coube a Fix-Zamudio, no México, e ao professor José Alfredo de Oliveira Baracho, no Brasil, pela teoria constitucionalista do processo.

Assim, o presente artigo busca demonstrar que o processo penal somente poderá obedecer ao devido processo constitucional-legal caso assegure às partes a devida e ampla participação na construção da sentença, buscando, nas origens do Estado Democrático de Direito, demonstrar que a participação dos sujeitos é imprescindível ao desenvolvimento da própria democracia e, consequentemente, do devido processo penal segundo os preceitos exigidos pela Constituição.

A investigação a ser empreendida não se cingirá a um único caminho metodológico, sob pena de serem elaborados juízos incompletos. Dessa maneira, valer-se-á de alguns métodos de pesquisa para promover um estudo mais denso e integral do argumento que é o objeto da pesquisa a ser desenvolvida. $\mathrm{O}$ artigo está inserido dentro da vertente metodológica jurídico-teórica. Nesta investigação, serão acentuados os aspectos conceituais, ideológicos e doutrinários e sua relação com a proteção da garantia fundamental ao devido processo legal. A pesquisa desenvolver-se-á orientada pelo método de abordagem dialético, pelo qual se busca penetrar no fenômeno investigado para explorar suas contradições e analisar as consequências que se projetam imediatamente sobre a realidade.

\section{ORIGENS DO ESTADO DEMOCRÁTICO DE DIREITO}

Desde a ruptura com o antigo regime absolutista, o Estado de Direito passou pelos paradigmas liberal, social e, por fim, democrá- 
tico, que trouxeram diferentes formas de interpretação dos institutos processuais, sobretudo na relação da sociedade com o Estado e, consequentemente, com o poder.

Sob o Estado Liberal, o Estado, em decorrência dos tempos vividos sob o absolutismo, era visto como adversário do ser humano, ${ }^{5}$ devendo tão somente salvaguardar as liberdades privadas do indivíduo e intervir o mínimo que fosse possível em sua liberdade, havendo completa separação entre Estado e Sociedade, ao passar por uma sociedade despolitizada e livre de interferências do Estado, que tinha que assegurar status negativo da liberdade de sujeitos de direito. ${ }^{6}$ As leis eram elaboradas pelos parlamentos e tinham como escopo a proteção e garantia da esfera privada dos indivíduos contra as interferências governamentais e particulares. " 'A lei, encarnação da vontade popular, não deveria sujeitar-se ao controle do Poder Judiciário, sob pena de instituição de um 'governo de juízes' de caráter antidemocrático". ${ }^{8}$ Nesse período, a atividade hermenêutica do juiz foi reduzida a uma função mecânica. $\mathrm{O}$ juiz era considerado como a "boca da lei" e a ele caberia apenas aplicar a lei ao caso concreto e a interpretação da lei deveria ser evitada. ${ }^{9}$

No Estado Liberal, há a prevalência da Função Legislativa ${ }^{10}$ sobre a Função Administrativa e Jurisdicional, ${ }^{11}$ já que essas funções eram tidas como meras executoras das normas elaboradas pelo legislador. ${ }^{12}$ O liberalismo processual idealizou o protagonismo das partes, uma vez que, desde a abertura do procedimento até o seu final, incluindo os atos de impulso procedimental, era confiado às partes. ${ }^{13}$ Contudo, a tutela dos direitos relacionados apenas com a liberdade, sobretudo a liberdade da burguesia, mostrou-se insuficiente para a tutela da dignidade humana. O Estado Liberal não conseguiu resolver o problema das classes proletárias e, por isso, entrou definitivamente em crise. ${ }^{14}$

O Estado Social, por sua vez, possuía natureza intervencionista, que requeria a constante presença do poder político nas instâncias sociais, ${ }^{15}$ aumentando, consequentemente, a dependência dos indivíduos em relação ao Estado. ${ }^{16} \mathrm{~A}$ atividade hermenêutica deixou de ser a mera aplicação mecanicista da lei e passou a adotar métodos mais complexos por meio das análises teleológicas, sistêmicas e históricas, na busca da vontade da lei e de sua aplicação de forma a materializar os direitos sociais, e o juiz passou a ser visto como garantidor das fi- 
nalidades sociais das quais o indivíduo era credor. ${ }^{17}$ No Estado Social, há, no processo jurisdicional, o protagonismo judicial, ${ }^{18}$ o que explica o surgimento, nesse período histórico, da teoria da relação jurídica por meio da obra de Büllow.

Nesse sistema, a função que prevalece é a Executiva (administrativa), pois caberia a ela fornecer os instrumentos para a intervenção do Estado na sociedade e assegurar o acesso aos direitos. ${ }^{19}$

Porém, ainda não era o suficiente, diante da sociedade moderna e de suas diversidades. O Estado passou a ser garante de direitos que não pertenciam a um ou alguns indivíduos, mas a todos. A participação dos interessados nas decisões tornou-se mais intensa e necessária.

O juiz passou de aplicador do Direito a construtor dele, pela participação das partes e da criação, pela decisão do caso posto perante ele, da norma que melhor se adapte ao caso concreto. “O juiz ou o decididor, nas democracias, não é livre intérprete da lei, mas o aplicador da lei como intérprete das articulações lógico-jurídicas produzidas pelas partes da estrutura procedimental". ${ }^{20}$

Em uma democracia não se devem aglutinar as funções nas mãos de um único e privilegiado intérprete. É impreterível que sejam repartidas as funções, atuando cada qual dentro da sua atribuição. Uma democracia se consolida no momento em que todas as funções republicanas verificam que a Constituição é a explicitação do próprio contrato social, o estatuto jurídico do político. ${ }^{21}$

A marca fundamental da democracia é a participação, calcada, sobretudo, na garantia dos direitos fundamentais de todos os indivíduos. Dessa forma, o Estado Democrático de Direito se constituirá no momento em que for assegurado a todos seus integrantes o acesso à participação em sua construção, de modo igual e sem discriminações ou preconceitos. Contudo, a participação deve se dar de forma organizada, para que seja assegurada a real participação de cada indivíduo. Aí nasce a importância do processo democrático.

Diante das mudanças do Estado Liberal ao Estado Democrático de Direito, o processo passou por diversas formas de interpretar suas normas. O Estado Democrático de Direito reclama do aplicador/ operador do Direito a participação na formação do provimento, mas 
apenas a participação não é o suficiente, o provimento deve ser precedido da simetria e do respeito aos direitos fundamentais e de acordo com a Constituição, sob pena de se ter uma decisão inconstitucional e desprovida de legitimidade.

Assim, no Estado Democrático de Direito, a função jurisdicional somente se concretizará dentro da estrutura constitucionalizada do processo. ${ }^{22}$ A tutela do processo é efetivada pelo reconhecimento da supremacia da Constituição sobre as normas processuais, ${ }^{23}$ e as garantias constitucionais atingem a todos os participantes do processo. ${ }^{24}$

O processo se posiciona ao centro da estrutura de atuação das garantias constitucionais e, concomitantemente, como instrumento de atuação dos modelos de "jurisdicionalidade plena" delineados pela Constituição como garantia democrática. ${ }^{25}$

\section{TEORIA DO PROCESSO E PROCESSO CONSTI- TUCIONAL DEMOCRÁTICO}

Por meio da obra de Bülow Teoria das exceções processuais e os pressupostos processuais (1868), segundo aponta Rosemiro Pereira Leal, o processo adquiriu autonomia em relação ao direito material. Bülow trabalhou os pressupostos processuais, de existência e desenvolvimento, pela relação entre autor, réu e juiz, que deveriam cumprir requisitos previstos na lei processual para a validade e legitimidade do processo. ${ }^{26}$

Essa teoria, que ainda predomina na confecção dos códigos e leis, foi aprimorada por juristas, como Chiovenda, Carnelutti, Calamandrei e Liebman, ${ }^{27}$ e teve grande influência no ordenamento jurídico brasileiro. ${ }^{28}$

Segundo a teoria da relação jurídica, o processo é uma relação intersubjetiva, dinâmica e de direito público, que tem por escopo permitir a apreciação do direito material pelo Estado-juiz. ${ }^{29}$ Bülow observou que a relação jurídica processual se distingue da relação de direito material em três aspectos: entre os sujeitos (autor, réu e Estado-juiz); pelo objeto (prestação jurisdicional); e por seus pressupostos (pressupostos processuais). ${ }^{30}$

Conforme apontou Carnelutti, o processo seria um conjunto de atos dirigidos à formação ou aplicação de normas jurídicas de caráter a 
permitir a participação das pessoas interessadas (partes) e das pessoas desinteressadas (juiz, auxiliares, peritos etc.), servindo o processo para a aplicação do Direito. ${ }^{31}$ Assim, os sujeitos processuais estabeleceriam relações jurídicas processuais para ordenar as atividades do processo para que esse possa se desenvolver. ${ }^{32}$

Por sua vez, Calamandrei afirmava que o processo seria uma série de atividades que deveriam ser levadas a cabo para se obter a providência jurisdicional, enquanto o procedimento seria, de forma singela, o aspecto exterior do fenômeno processual. ${ }^{33}$

Da teoria da relação jurídica deriva a concepção instrumentalista do processo, segundo a qual o processo seria instrumento da jurisdição na busca da paz social, ${ }^{34}$ possuindo, assim, escopos metajurídicos.

Para a teoria da relação jurídica, o processo seria visto pelos atos que lhe dão corpo e pelas relações entre esses atos e os sujeitos do processo. Por sua vez, procedimento seria tão só o meio extrínseco pelo qual se desenvolveria o processo. ${ }^{35}$

Verifica-se que os adeptos da Teoria da Relação Jurídica e de sua ramificação por meio da escola instrumentalista se perdem ao tentar distinguir processo de procedimento. De grande valia é a crítica apresentada por Rosemiro Pereira Leal que, em sua obra, afirma que os adeptos dessa teoria fazem uma tormentosa confusão entre processo e procedimento e, na tentativa de distingui-los, hermetizam os conceitos de Bülow e não explicam qual seria o meio pelo qual se desenvolveria o processo. ${ }^{36}$

Verifica-se que, na teoria da relação jurídica, o processo é o gênero e o procedimento é a espécie, tal qual se verifica nos Código de Processo Civil ${ }^{37}$ e no Código de Processo Penal ${ }^{38}$ brasileiros.

Contudo, a teoria da relação jurídica mantém a jurisdição como atividade do juiz, vinculando o juiz e as partes e definindo-lhes sujeição, poderes, direitos e obrigações, ${ }^{39}$ mantendo, dessa forma, as partes em relação de subordinação ao julgador, gerando o que André Cordeiro Leal aponta como sendo o paradoxo de Bülow. ${ }^{40}$

A subordinação das partes com referência ao julgador, na teoria da relação jurídica, acaba por levar essa teoria ao encontro do estado social que, como vimos, é marcado pela figura provedora do ente 
estatal. Contudo, essa teoria não pode ser hábil a servir à democracia constitucional, eis que não permite a devida participação de todos os sujeitos processuais (juiz e partes) em plano de isonomia na construção do provimento.

Visando a quebrar a posição de hierarquia entre o juiz e as partes, que restou da teoria iniciada por Bülow, o professor italiano Elio Fazzalari rompeu com a teoria da relação jurídica e formulou a teoria do processo como procedimento que se desenvolve em contraditório, segundo a qual diferencia claramente o processo do procedimento.

Como anota Aroldo Plínio Gonçalves, o processo, como procedimento em contraditório entre as partes, não é compatível com o conceito de relação jurídica. Isso se dá porque o conceito de relação jurídica é marcado pelo vínculo de exigibilidade, de subordinação. Uma garantia não é uma imposição; é uma liberdade protegida. Se o contraditório é uma garantia, não poderia ser conciliado como o conceito de relação jurídica. ${ }^{41}$

Dessa forma, Fazzalari rompeu com a teoria da relação jurídica ${ }^{42}$ e, ao colocar o processo como procedimento em contraditório, redefiniu o processo e o procedimento, passando aquele a ser espécie de procedimento, quando este possuir a marca característica do contraditório. ${ }^{43}$

Nesse sentido, Rosemiro Pereira Leal afirma que aceitar irrefletidamente o ensino de Bülow até Liebman e, consequentemente, dos adeptos da concepção instrumentalista de processo, permitiria entregar a aplicação do Direito a uma justiça de portadores natos de saberes oriundos de uma entidade irretocável e de uma experiência de vida irretocável. ${ }^{44}$

Importante, portanto, diferenciar o procedimento do processo segundo a concepção fazzalariana. Desse modo, para Fazzalari:

[...] o 'procedimento' se verifica quando se está de frente a uma série de normas, cada uma das quais reguladora de uma determinada conduta (qualificando-a como lícita ou obrigatória), mas que enunciam como condição da sua incidência o cumprimento de uma atividade regulada por outra norma da série, e assim por diante, até a norma reguladora de um 'ato final' ${ }^{45}$ 
Por sua vez, o processo, na concepção de Fazzalari, “[...] é um procedimento do qual participam (são habilitados a participar) aqueles em cuja esfera jurídica o fato final é destinado a desenvolver efeitos: em contraditório, e de modo que o autor do ato não possa obliterar as suas atividades". ${ }^{46}$ Essa percepção de processo, como espécie do gênero procedimento, permitiu a Fazzalari estabelecer também subespécies do processo: legislativo, administrativo e jurisdicional. ${ }^{47}$

Contudo, conforme crítica apresentada por Rosemiro Pereira Leal, Fazzalari, ao conceber o processo como o procedimento realizado em contraditório, não o fez segundo uma reflexão constitucional de direito-garantia (teoria constitucionalista do processo) ou de instituição constitucionalizada regente dos procedimentos (teoria neoinstitucionalista do processo). ${ }^{48}$

Coube ao professor mexicano Héctor Fix-Zamudio iniciar os estudos relacionando constituição e processo. No Brasil, os estudos do processo constitucional foram capitaneados pelo professor mineiro José Alfredo de Oliveira Baracho. ${ }^{49}$ Baracho aponta que a Constituição determina muitos dos institutos básicos do processo, havendo ligação direta, portanto, entre o processo e a Constituição. ${ }^{50}$

Segundo a teoria constitucionalista, o processo apresenta-se como instituição constitucionalizada que possui principiologia constitucional do devido processo constitucional. Abrangendo o processo legal, os princípios da ampla defesa, isonomia e contraditório, o processo converte-se em direito-garantia, representando conquistas teóricas da humanidade no combate à tirania. ${ }^{51} \mathrm{O}$ processo constitucional não é somente um direito instrumental, mas verdadeira metodologia de garantia dos direitos fundamentais. ${ }^{52}$

Como anota Marcelo Cunha de Araújo, o devido processo constitucional democrático, em uma visão do processo jurisdicional, seria o conjunto mínimo de características trazidas pela Constituição, que conferem ao processo o título de direito-garantia fundamental do cidadão, permitindo sua participação política na aplicação do Direito. ${ }^{53}$

O processo jurisdicional coloca-se ao centro da estrutura de atuação das garantias constitucionais e, ao mesmo tempo, como instrumento da atuação dos modelos de jurisdicionalidade plena delineados por 
ela. ${ }^{54} \mathrm{O}$ processo, no Estado Democrático de Direito, é garantia constitutiva dos direitos fundamentais. ${ }^{55}$ As referidas garantias constitucionais do processo permeiam e abrangem todos os seus participantes. ${ }^{56}$

Ronaldo Brêtas de Carvalho Dias aponta que a viga mestra do Processo Constitucional encontra-se no devido processo legal, que deve ser entendido como os direitos de ação (direito à jurisdição); direito de ampla defesa; direito à defesa por advogado; direito ao processo sem dilações indevidas; direito à decisão proferida por órgão jurisdicional previamente definido pela Constituição e fundamentado no ordenamento jurídico; direito aos recursos. ${ }^{57}$

Pelo processo constitucional, o direito de ação e o de defesa são assegurados de forma completa a todos os indivíduos, devendo o processo ser justo e leal. ${ }^{58}$ Dizer que o processo deve ser justo significa que deve ser organizado segundo as regras que respeitem as garantias fundamentais, primordialmente o contraditório, ${ }^{59}$ que significa mais que o simplista dizer e contradizer (bilateralidade de audiência), como faz crer a concepção instrumentalista do processo. ${ }^{60}$

No Estado Democrático de Direito, o contraditório passa a ser percebido como direito de influência (e efetiva participação) das partes na formação da decisão, ${ }^{61}$ que gera a garantia da não surpresa, ou seja, a garantia que a parte tem de não ser afetada por decisão da qual não participou efetivamente de sua construção. ${ }^{62}$

O direito de ação é considerado um direito de natureza pública com origem na Constituição, consolidando-se pela compreensão de que todas as pessoas têm direito de obter, de forma efetiva, a tutela jurisdicional, na concretização e exercício de seus direitos e interesses legítimos. ${ }^{63}$ "O direito de ação é um direito fundamental do homem" ${ }^{64}$

O direito de ação relaciona-se diretamente com o direito de pedir, configurando-se como o direito de reclamar a efetivação do direito de reclamar por meio de um processo judicial. ${ }^{65}$

Dessa forma, o direito ao processo, ou direito à tutela jurisdicional, é tido como garantia consagrada pela Constituição, ${ }^{66}$ complementado pelo direito de obter uma decisão de mérito. ${ }^{67}$ Dessa forma, a jurisdição é, no Estado Democrático de Direito, direito fundamental das pessoas (naturais ou jurídicas). Em contrapartida, é atividade-dever 
do Estado exercida por seus órgãos competentes mediante petição daquele que invoca e garantia fundamental do processo constitucional. ${ }^{68}$

Há que ser ressaltado que o processo somente será justo caso não exista hierarquia entre as partes e o julgador. ${ }^{69}$ As partes e o juiz são iguais, ${ }^{70}$ devendo agir em igualdade na construção do provimento. A isonomia entre os sujeitos processuais decorre diretamente do contraditório, uma das vigas mestras do processo constitucional, que possibilita a simétrica participação igualitária das partes na preparação do provimento jurisdicional. ${ }^{71}$

Verifica-se, portanto, que o Processo Constitucional é umbilicalmente ligado ao devido processo legal, assentando-se em princípios processuais estabelecidos pela Constituição, ${ }^{72}$ que consolidam uma concepção prática do Processo Constitucional. ${ }^{73}$

\section{O DEVIDO PROCESSO LEGAL E A PARTICIPA- ÇÃO DOS SUJEITOS PROCESSUAIS NO PROCES- SO PENAL DEMOCRÁTICO}

Cabe ao devido processo legal, consoante Rosemiro Pereira Leal, estabelecer o espaço discursivo de legitimação da decisão, que será preparada pela participação de todos os sujeitos do processo. ${ }^{74}$

Dessa forma, para que o processo possa viabilizar um espaço de manifestação da cidadania e seja realmente democrático, o que ocorrerá pela participação simétrica das partes na construção do provimento, mudanças devem ser realizadas, sobretudo no processo jurisdicional e, mais precisamente, no comportamento dos sujeitos do processo com fim de garantir a efetiva participação.

Fazzalari, pela teoria do processo como procedimento em contraditório, rompeu com a teoria da relação jurídica e retirou o juiz da posição superior da relação jurídico-processual para inseri-lo em igualdade em relação às partes.

Assim, o Estado constitucional democrático, conforme salienta Dierle José Coelho Nunes, garante a participação permanente e efetiva dos sujeitos de direitos na formação dos provimentos aos quais estarão sob os efeitos. ${ }^{75}$ 
A retirada do juiz do centro do palco processual não esvazia o papel da magistratura, mas o redefine. $\mathrm{O}$ juiz deve ser um garantidor de direitos fundamentais, entre os quais se encontra o direito de participação dos sujeitos na formação do provimento. O juiz democrático não pode omitir-se em relação à realidade social, assumindo função decisória segundo as regras e princípios do sistema processual, e deve assegurar que o provimento seja extraído do debate endoprocessual pelo qual todos os sujeitos possam, por seus argumentos, influenciar a construção da decisão. ${ }^{76}$

O juiz, segundo aponta Aroldo Plínio Gonçalves, é sujeito do processo, tendo a titularidade dos provimentos, contudo sua participação no processo não o faz contraditor, ou seja, o juiz não participa da relação processual em contraditório com as partes. ${ }^{77}$ No entanto, como explicitamos acima, o juiz tem o dever de fundamentar sua decisão e analisar todas as teses apresentadas pelas partes, uma vez que somente por meio da fundamentação é que será assegurado o contraditório e a ampla defesa.

Como vimos, o processo liberal foi marcado pela superioridade das partes em detrimento do juiz, sendo o processo um diálogo das partes assistido pelo juiz a quem competia apenas aplicar a lei ao caso concreto. Já o processo do Estado Social teve como característica a prevalência do Estado-Juiz sobre as partes, em um monólogo jurisdicional que era assistido pelas partes. No Estado Democrático de Direito, não se pode permitir nem que o juiz seja o principal sujeito processual e nem que as partes o sejam. Devem ambos, juiz e partes, atuar em conjunto e de forma a constituir, por meio do diálogo, o provimento final.

Assim, em uma visão constitucional democrática, não existe entre os sujeitos do processo relação de submissão, mas de interdependência, o que torna inaceitáveis concepções que colocam as partes submissas ao juiz. ${ }^{78}$

O juiz não é o único garantidor da democracia e nem o mais avalizado, ao contrário do que afirma José Renato Nalini. ${ }^{79}$ A democracia é de todos e compete ao povo sua manutenção e, no processo, competirá essa tarefa a todos seus sujeitos.

Nesse contexto, o juiz é funcionário do povo; não é construtor do Direito, mas concretizador do provimento, 80 “[...] não é livre intérprete da lei, mas o aplicador da lei como intérprete das articulações 
lógico-jurídicas produzidas pelas partes construtoras da estrutura procedimental". ${ }^{81}$

Segundo ressalta Alexandre de Morais da Rosa, o juiz não pode, no processo, realizar os anseios sociais; deve manter-se de maneira imparcial e garantir o equilíbrio do contraditório, assegurando, assim, a democracia processual. ${ }^{82}$

Dessa forma, no Estado Democrático de Direito, o juiz justiceiro, que se coloca como protagonista do processo, não tem lugar. Atualmente, o julgador deve pautar-se pela abertura para a participação, colocando-se em igualdade com os demais sujeitos do processo.

Os órgãos jurisdicionais devem também cumprir as normas, principalmente os prazos a eles destinados, contribuindo, assim, para a almejada celeridade procedimental. ${ }^{83}$

Essa mudança de postura, porém, compete também às partes, principalmente a seus procuradores, que devem se colocar como garantes do contraditório e, consequentemente, da democracia.

Segundo aponta Carlos Henrique Soares, o advogado é pressuposto para a garantia dos direitos fundamentais, estabelecendo o efetivo contraditório no processo jurisdicional e garantindo o devido processo legal. O advogado, nesse diapasão, é o responsável pelo reconhecimento das partes como autores e destinatários do provimento jurisdicional, ${ }^{84}$ percebendo-se, agindo e tornando-se, dessa forma, realmente indispensável à administração da Justiça, como prescreve o art. 133 da Constituição da República Federativa do Brasil.

Dessa maneira, verifica-se que o processo constitucional está a exigir uma mudança de comportamento tanto dos juízes como dos advogados. Aos juízes cumpre deixar a postura messiânica e aos advogados, perceberem-se em igualdade em relação aos magistrados. Aos juízes, aos advogados e às partes cumpre o dever de se postarem de forma a construírem, juntos, o provimento.

O que se está a propor é que o processo seja regido pelo contraditório e, com base nele, se implemente o diálogo entre todos os sujeitos processuais, evitando-se decisões-surpresa por parte do juiz e a imposição de argumentos estratégicos e persuasivos por uma parte mais bem assessorada tecnicamente. 
O princípio do contraditório, que é descrito pela concepção instrumentalista do processo como sendo tão somente o direito de informação e reação em relação aos atos processuais, ${ }^{85}$ em uma visão constitucional do processo, vai muito além.

Rosemiro Pereira Leal aponta, em sua obra, que o princípio do contraditório pode ser traduzido pela dialogicidade necessária entre as partes para que defendam ou disputem o direito alegado. ${ }^{86}$

Segundo o modelo constitucional de processo, o contraditório é concebido sob dupla acepção: de um lado, o princípio da não surpresa e, de outro, o princípio da influência, pois aquele é decorrente direto deste. ${ }^{87}$

Pelo princípio da influência, as partes, com a participação em simétrica paridade, têm o direito de influir diretamente no provimento, fazendo-o pela exposição fundamentada de seus argumentos. Segundo Lênio Streck, " [...] o contraditório passa a ser a garantia da possibilidade da influência (e efetiva participação) das partes na formação da resposta judicial, questão que se refletirá na fundamentação da decisão". 88

Já a segunda face do princípio do contraditório, o princípio da não surpresa, garante que as partes não sejam afetadas por uma decisão da qual não tenham participado efetivamente de sua construção. ${ }^{89}$

Em decorrência desse princípio, as partes têm o direito de ver todas as suas teses apreciadas pela decisão, ainda que sejam refutadas. Tornam-se insustentáveis no Estado Democrático de Direito concepções de que o julgador não estaria obrigado a apreciar todas as teses expostas pela parte, infelizmente ainda predominante nos tribunais pátrios. ${ }^{90}$

Contudo, louváveis decisões vêm renovando as esperanças de que o contraditório demande a ampla fundamentação e análise de todas as teses expostas pelas partes, fazendo valer o disposto no art. 93, IX, da Constituição Brasileira.

Nesse sentido, vale citar as decisões emanadas do Supremo Tribunal Federal no julgamento do Habeas Corpus n ${ }^{\circ} 74.073$, rel. Min. Celso de Mello, ${ }^{91}$ e no acórdão do Mandado de Segurança n ${ }^{\circ}$ MS-24.268-0, rel. Min. Ellen Gracie, rel. para acórdão Min. Gilmar Mendes, de qual se extrai o seguinte trecho do voto do Min. Gilmar Mendes: 
Sobre o direito de ver os seus argumentos contemplados pelo órgão julgador (Recht auf Berïcksichtigung), que corresponde, obviamente, ao dever do juiz ou da Administração de a eles conferir atenção (Beachtenspflicht), pode-se afirmar que envolve não só o dever de tomar conhecimento (Kenntnisnahmepflicht), como também o de considerar, séria e detidamente, as razões apresentadas (Erwägungspflicht).

Por fim, vale destacar, conforme leciona André Cordeiro Leal, que o contraditório é que proporcionará uma atuação equitativa dos sujeitos no procedimento jurisdicional, garantindo, em conjunto com o princípio da fundamentação das decisões jurisdicionais, uma decisão forjada no Direito debatido entre as partes e nos fatos reconstruídos. ${ }^{92}$

Toda essa evolução atinge também o processo penal que desde muito trabalha de forma pendular entre o sistema acusatório e o sistema inquisitório. No primeiro, acusatório, o juiz é um sujeito passivo, separado das partes, e o julgamento é precedido de um debate paritário iniciado pela acusação, que assume todo o ônus da prova, seguido pela defesa em contraditório público. Por sua vez, o sistema inquisitório é aquele em que o juiz procede de ofício à procura de provas, tendo, portanto, postura ativa na produção de provas e no julgamento. ${ }^{93} \mathrm{No}$ sistema inquisitorial, o juiz, para combater inimigos ocultos, converte-se em órgão militante. ${ }^{94}$

A principal e única diferença entre os sistemas inquisitório e acusatório remete à extrema concentração de poder nas mãos do órgão julgador, no sistema inquisitório, no qual o julgador recolhe a prova, antes de qualquer outro sujeito, e determina sua produção, enquanto, no sistema acusatório, o juiz tem a função de garantir as regras do jogo e cabe às partes a apresentação das provas licitamente obtidas. ${ }^{95}$

No Processo Penal, essa interferência do juiz na produção da prova não é simples. Isso porque a prova compete originalmente às partes, sobretudo àquela que realiza a acusação, eis que, por imperativo constitucional, deve-se presumir sua não culpabilidade. Assim, a interferência do julgador somente se daria de forma complementar, quando houvesse dúvidas, ${ }^{96}$ porém, havendo dúvidas, ao julgador é imposta a sentença absolutória, ${ }^{97}$ uma vez que, se não há provas para embasar a condenação, desnecessária a produção da prova e supletiva 
à atividade acusatória, pois, em qualquer das hipóteses, sua produção irá contra o próprio Estado Democrático de Direito.

Porém, não é o que percebemos no Processo Penal Brasileiro que, apesar de contar com uma Constituição que implicitamente aponta para a adoção do modelo acusatório, possui um Código de Processo Penal francamente inquisitorial forjado pelo autoritarismo de Vargas que é o reflexo turvo do Código de Processo Penal Italiano de 1933, escrito pelos irmãos Rocco, a pedido de Manzini (ministro da Justiça), e encomendado por Mussolini. Dessa forma, o vigente Código possibilita ao juiz a gestão da prova em todas as fases do processo (art. 156); a prisão preventiva de ofício (art. 311); discordar do pedido de arquivamento realizado pelo Ministério Público (art. 28), entre outros exemplos. Verifica-se, então, que vivemos um processo penal de dupla personalidade, que possui vontade constitucional de ser acusatório, mas com espírito inquisitório, prevalecendo, na prática, o espírito em detrimento da vontade. Tal situação não foi e nem será alterada pelas reformas pontuais, apenas a mudança integral do código alterará suas origens e sua alma, pois somente um código nascido para a democracia será capaz de mudar o quadro.

No processo penal democrático, o contraditório deverá guardar a igualdade de oportunidades, isonomia, o que exige a revisão de diversas regras do Código de Processo Penal, principalmente aquelas que delimitam a produção da prova. ${ }^{98}$

Se o acusado é presumidamente não culpado, ${ }^{99}$ todo o procedimento deve seguir essa máxima, devendo o agente ministerial, ao propor a ação penal e durante o procedimento, apresentar provas de que é o indivíduo culpado. Já à defesa compete apenas refutar as argumentações acusatórias, já que, diante da dúvida, a presunção de não culpabilidade permanece íntegra. Assim sendo, é “[...] vedada ao juiz a ingerência no conteúdo probatório, o Ministério Público deve desempenhar com exclusividade a tarefa de acusar e, em última análise, de provar a culpa do acusado ${ }^{100}$."

Assim, resta claro que o juiz não poderá, no processo penal democrático, assumir o centro da atividade, mas terá que dividir o palco com as partes, a quem competirá a atividade probatória, sobretudo a parte responsável pela acusação. Não se admite, no processo penal democrático, um juiz que assuma a posição de herói da sociedade, ${ }^{101}$ 
pois, por mais bem intencionado que pareça, não é papel do julgador a proteção da sociedade, mas o julgamento imparcial ${ }^{102}$ e segundo a prova produzida em contraditório.

Somente poderia ser dado ao julgador a produção da prova no caso de ser prova favorável à defesa, quando todo conjunto probatório levar à condenação e somente a prova não produzida pela defesa puder mudar a decisão. Isso se deve ao fato de que a presunção de não culpabilidade deve ser preservada e somente quebrada com absoluta segurança.

Ao juiz, no processo penal democrático, compete a tarefa árdua de assegurar o contraditório (influência e não surpresa), ${ }^{103}$ garantindo a existência do próprio processo, por ser aquele um de seus princípios institutivos. ${ }^{104} \mathrm{O}$ juiz deve atuar como garantidor dos direitos fundamentais inseridos ou resultantes da Constituição, 105 resguardando, sobretudo, o direito de participação dos demais sujeitos processuais na construção do provimento penal. Somente dessa forma se assegurará uma decisão argumentativamente participada, em que as partes possam, pelo debate aberto, participar da construção da decisão.

Ao garantir o contraditório, o juiz estará assegurando às partes, pela participação simétrica, a ampla defesa e a isonomia, ${ }^{106}$ possibilitando, desse modo, a existência do processo nos termos previstos pela Constituição.

Mais que isso, para que seja assegurado o contraditório, que deixou de ser a defesa negativa (resistência) para passar a ser o direito de influenciar o desenvolvimento do processo, ${ }^{107}$ a decisão deve ser fundamentada, 108 pois a fundamentação é indissociável do contraditório ${ }^{109}$ e somente haverá a participação se a decisão apresentar a argumentação dos afetados. Portanto, é inaceitável a decisão simplista que não expõe claramente todas as teses trazidas pelas partes.

\section{CONCLUSÃO}

O Estado Democrático de Direito é fruto das conquistas históricas da sociedade que, por meio de avanços e retrocessos, uniu o princípio democrático com o princípio do Estado de Direito. 
O Estado Democrático de Direito demanda a participação na formação do provimento. Isso somente é possível fazer por meio do processo.

A teoria da relação jurídica, que deu origem à concepção instrumentalista do processo e, ainda hoje, tem adeptos de renome no Brasil, insere o juiz em posição de supremacia em relação aos demais sujeitos do processo.

Fazzalari rompeu com a teoria da relação jurídica, porém não o fez de forma constitucionalizada, o que coube a Fix-Zamudio, no México, e ao professor José Alfredo de Oliveira Baracho, no Brasil, pela teoria constitucionalista do processo.

A decisão somente será legitimada pelo processo com a obediência ao devido processo legal. O que, em razão do contraditório, obriga que o julgador analise todas as teses levadas ao contraditório. Infelizmente, essa posição não é majoritária, mas alguns acórdãos já foram proferidos nesse sentido.

A efetivação do processo constitucional democrático e do devido processo legal, no processo jurisdicional, demanda mudança de postura dos sujeitos do processo, devendo o juiz deixar o centro do palco processual para contracenar com os demais sujeitos; e os advogados postarem-se de forma independente e em posição de igualdade em relação ao julgador.

O Processo Penal também é atingido por essa reviravolta constitucional democrática, colocando o juiz para contracenar, em igualdade, com as partes. Assim, o juiz penal não detém os poderes da gestão probatória, tendo a função, não menos importante, de assegurar às partes a isonomia necessária para o desenvolvimento do procedimento em contraditório (processo).

\section{NOTAS}

1 BARACHO, José Alfredo de Oliveira. Processo constitucional: aspectos contemporâneos. Belo Horizonte: Fórum, 2008. p. 57. BARACHO, José Alfredo de Oliveira. Teoria geral do processo constitucional. Revista da Faculdade Mineira de Direito, p. 127.

2 ANDOLINA, Italo. O papel do processo na atuação do ordenamento constitucional e transnacional. Revista de Processo, São Paulo, v. 87, p. 63-69, jul./set. 1997. p. 66. 
3 Nesse sentido, Paulo Bonavides (1993, p. 27) lembra: “Na doutrina do liberalismo, o Estado foi sempre o fantasma que atemorizou o indivíduo. O poder, de que não pode prescindir o ordenamento estatal, aparece, de início, na moderna teoria constitucional como o maior inimigo da liberdade".

4 HABERMAS, Jürgen. Direito e democracia: entre facticidade e validade. Rio de Janeiro: Tempo Universitário, 1997. v. II, p. 132.

5 DEL NEGRI, André. Controle de constitucionalidade no processo legislativo: teoria da legitimidade democrática. 2. ed. Belo Horizonte: Fórum, 2008. p. 33.

6 SARMENTO, Daniel. Os direitos fundamentais nos paradigmas liberal, social e pós-social (pós-modernidade constitucional?). In: SAMPAIO, José Adércio Leite (Coord.). Crise e desafios da Constituição. Belo Horizonte: Del Rey, 2004. cap. 18, p. 375-414, p. 382.

7 CARVALHO NETO, Menelick. A hermenêutica constitucional sob o paradigma do Estado Democrático de Direito. In: OLIVEIRA, Marcelo Andrade Cattoni de (Coord.). Jurisdição e hermenêutica constitucional. Belo Horizonte: Mandamentos, 2004, p. 25-44, p. 34.

8 Preferimos a expressão "função" ao consagrado termo "poder", pois entendemos que o poder é uno e originado do povo. O que se divide são as atribuições de funções. Como afirma Ronaldo Brêtas de Carvalho Dias: “O Estado deve ser concebido como ordenação de várias funções atribuídas a órgãos diferenciados, segundo a previsão das normas constitucionais que o organizam juridicamente. O que deve ser considerada repartida ou separada é a atividade e não o poder do Estado, do que resulta uma diferenciação de funções exercidas pelo Estado por intermédio de órgãos criados na estruturação da ordem jurídica constitucional, nunca a existência de vários poderes do mesmo Estado" (BRÊTAS, 2004, p. 70).

9 Álvaro Ricardo de Souza Cruz anota, citando as ideias de Montesquieu, que a função executiva "[...] deveria ser exercida por um monarca, haveria de limitar-se a aplicar os ditames legais [...]. O Judiciário, ao decidir, deveria simplesmente aplicar ao caso concreto uma decisão política, fixada anteriormente pelo legislador" (CRUZ, 2004, p.73).

10 SARMENTO, Daniel, op. cit., p. 393.

11 NUNES, Dierle José Coelho. Processo jurisdicional democrático. Curitiba: Juruá Editora, 2010. p. 76-77

12 A crise do Estado-Mínimo chegou ao seu ápice com a Primeira Guerra Mundial, seguida da quebra da Bolsa de Valores de Nova Iorque, 1929, e a Grande Depressão. A crise trouxe a necessidade de intervenção do Estado na vida social, como ocorreu com o New Deal. Também nesse período, os direitos sociais passaram a ser reconhecidos, sobretudo com as Constituições do México (1917) e de Weimar (1919), advindo daí o Estado Social, sob forte incentivo da Encíclica Rerum Novarum do papa Leão XIII (BONAVIDES, 1993, p. 34).

13 HABERMAS, Jürgen, op. cit., p. 132.

14 BONAVIDES, Paulo. Do Estado Liberal ao Estado Social. 3. ed. Belo Horizonte: Del Rey, 1993. p. 196.

15 CARVALHO NETO, Menelick, 2004, p. 83.

16 NUNES, Dierle José Coelho, 2010, p. 86.

17 SARMENTO, Daniel, op. cit., p. 393.

18 LEAL, Rosemiro Pereira. Teoria geral do processo: primeiros estudos. 9. ed. Rio de Janeiro: Forense, 2010. p. 63.

19 STRECK, Lênio Luiz. Hermenêutica, Constituição e Processo, ou de "como discricionariedade não combina com democracia"; o contraponto da resposta correta. In: MACHADO, Felipe Daniel Amorim; CATTONI DE OLIVEIRA, Marcelo Andrade (Coord.). Constituição e processo: a contribuição do processo ao constitucionalismo brasileiro. Belo Horizonte: Del Rey, 2009. p. 3-27.

20 BRÊTAS, Ronaldo de Carvalho Dias. Responsabilidade do Estado pela função jurisdicional. Belo Horizonte: Del Rey, 2004. p. 84.

21 BARACHO, José Alfredo de Oliveira. Processo constitucional. Revista Forense, Rio de Janeiro, v. 337, p. 105-123, jan/mar. 1997. p. 105.

22 Ibidem, p. 105-106.

23 ANDOLINA, Italo, op. cit., p. 65. 
24 Bülow não criou o conceito de relação jurídica processual, mas buscou-o nos textos de Búlgaro, jurista italiano do século XII, que afirmava que o processo (juízo) é o ato de três pessoas: juiz, autor e réu (iudicium est actus trium presonarum: iudicis, actoris et rei.) (Cf. LEAL, 2002, p. 161).

25 LEAL, Rosemiro Pereira, 2010, p. 78.

26 Libman veio para o Brasil como refugiado durante a Segunda Guerra Mundial (1939-1945) e lecionou Processo Civil na Faculdade de Direito da Universidade de São Paulo, tendo como aluno Alfredo Buzaid, responsável pela elaboração do Código de Processo Civil vigente (1973).

27 CÂMARA, Alexandre Freitas. Lições de direito processual civil. 11. ed. Rio de Janeiro: Lumen Juris, 2004. p. 135.

28 CINTRA, Antônio Carlos de Araújo; GRINOVER, Ada Pellegrini; DINAMARCO, Cândido Rangel. Teoria geral do processo. 15. ed. São Paulo: Malheiros, 1999. p. 278.

29 CARNELUTTI, Francesco. Instituiciones del proceso civil. Buenos Aires: Ediciones Juridicas Europa-America (E.J.E.A), 1959. v.1, p. 21-22.

30 Idem, p. 290.

31 CALAMANDREI, Piero. Instituciones de derecho procesal civil, v. 1. Buenos Aires: Ediciones Juridicas Europa-America (E.J.E.A), 1962. v. 1, p. 317-318.

32 CINTRA, Antônio Carlos de Araújo; GRINOVER, Ada Pellegrini; DINAMARCO, Cândido Rangel, op. cit., p. 41.

33 Ibidem, p. 275.

34 LEAL, Rosemiro Pereira, op. cit., p. 78-79.

35 Vg. art. 270-273 do Código de Processo Civil brasileiro.

36 Vg. art. 394 do Código de Processo Penal brasileiro, redação dada pela Lei nº 11.719/2008.

37 BRÊTAS, Ronaldo de Carvalho Dias. Exame técnico e sistemático do Código de Processo Civil reformado. In: BRÊTAS, Ronaldo de Carvalho Dias; DINIZ NEPOMUCENO, Luciana (Coord.). Processo civil reformado. Belo Horizonte: Del Rey, 2009. p. 407-456, p. 420.

38 LEAL, André Cordeiro. Instrumentalidade do processo em crise. Belo Horizonte: Mandamentos, 2008. p. 29.

39 GONÇALVES, Aroldo Plínio. Técnica processual e teoria do processo. Rio de Janeiro: Aide, 1992. p. 132.

40 LARA, Leonardo Augusto Leão; CARVALHO, Newton Teixeira de; PENNA, Saulo Versiani. Processo, ação e jurisdição em Fazzalari. In: LEAL, Rosemiro Pereira. Estudos continuados de processo. São Paulo: IOB Thonsom, 2004. v. V, p. 243-348, p. 259.

41 FAZZALARI, Elio. Instituições de direito processual. Campinas: Bookseller, 2006. p. 93.

42 LEAL, Rosemiro Pereira. Modelos processuais e constituição democrática. In: MACHADO, Felipe Daniel Amorim; CATTONI DE OLIVEIRA, Marcelo (Coord.). Constituição e processo: a contribuição do processo ao constitucionalismo brasileiro. Belo Horizonte: Del Rey, 2009. p. 289.

43 FAZZALARI, Elio, op.cit., p. 93.

44 Ibidem, p. 118-119.

45 GONÇALVES, Aroldo Plínio, op. cit., p. 115.

46 LEAL, Rosemiro Pereira, op. cit., p. 83.

47 Ibidem, p. 84.

48 BARACHO, José Alfredo de Oliveira. Processo Constitucional. Rio de Janeiro: Forense, 1984. p. 122.

49 LEAL, Rosemiro Pereira, op. cit., p. 85.

50 BARACHO, José Alfredo de Oliveira, op. cit., p. 47.

51 ARAÚJO, Marcelo Cunha de. O novo processo constitucional. Belo Horizonte: Mandamentos, 2003. p. 97-98.

52 ANDOLINA, Italo. O papel do processo na atuação do ordenamento constitucional e transnacional. Revista de Processo, São Paulo, v. 87, p. 65, 1998.

53 BARROS, Flaviane de Magalhães. O modelo constitucional de processo e o processo penal: a necessidade de uma interpretação das reformas do processo penal a partir da Constituição. In: MACHADO, Felipe Daniel Amorim; CATTONI DE OLIVEIRA, Marcelo Andrade (Co- 
ord.). Constituição e processo: a contribuição do processo ao constitucionalismo brasileiro. Belo Horizonte: Del Rey, 2009. p. 331-345, p. 332.

54 BARACHO, José Alfredo de Oliveira. Teoria geral do processo constitucional. Revista da Faculdade Mineira de Direito, v. 2, p. 90, 1999.

55 BRÊTAS, Ronaldo de Carvalho Dias, 2009, p. 437-468. BRÊTAS, Ronaldo de Carvalho Dias. Direito à jurisdição eficiente e garantia da razoável duração do processo no Estado Democrático de Direito. In: GALUPPO, Marcelo Campos (Org.). O Brasil que queremos: reflexões sobre o Estado Democrático de Direito. Belo Horizonte: Editora Puc/Minas, 2006. p. 653-663, p. 655.

56 BARACHO, José Alfredo de Oliveira, 2008, p. 57. BARACHO, José Alfredo de Oliveira, 1999, p. 127.

57 ANDOLINA, Italo, 1997, p. 66.

58 THEODORO JÚNIOR, Humberto. Curso de direito processual civil. 39. ed. Rio de Janeiro: Forense, 2003. v. 1, p. 24.

59 STRECK, Lênio Luiz. Hermenêutica, constituição e processo, ou de "como discricionariedade não combina com democracia"; o contraponto da resposta correta. In: MACHADO, Felipe Daniel Amorim; CATTONI DE OLIVEIRA, Marcelo Andrade (Coord.). Constituição e processo: a contribuição do processo ao constitucionalismo brasileiro. p. 19. NUNES, Dierle José Coelho. Processo jurisdicional democrático. p. 227.

60 BARROS, Flaviane de Magalhães, 2009, p. 229.

61 BARACHO, José Alfredo de Oliveira, 1999, p. 90. BARACHO, José Alfredo de Oliveira, 1997, p. 107.

62 BARACHO, José Alfredo de Oliveira, 1999, p. 118.

63 Ibidem, p. 118.

64 Vg. art. $5^{\circ}, \mathrm{XXXV}$, da Constituição da República Federativa do Brasil.

65 BARACHO, José Alfredo de Oliveira, 1999, p. 94.

66 BRÊTAS, Ronaldo de Carvalho Dias. Exame técnico e sistemático do Código de Processo Civil reformado. In: BRÊTAS, Ronaldo de Carvalho Dias; DINIZ NEPOMUCENO, Luciana (Coord.), 2009, p. 420. BRÊTAS, Ronaldo de Carvalho Dias. A garantia da fundamentação das decisões jurisdicionais no Estado Democrático de Direito. Revista da Faculdade Mineira de Direito, Belo Horizonte, v. 8, n. 16, p. 147-161, 2 sem/2005, p. 149.

67 BARACHO, José Alfredo de Oliveira, 2008, p. 57. BARACHO, José Alfredo de Oliveira, 1999, p. 127.

68 No Processo Constitucional, não se pode mais aceitar que o juiz seja considerado superior em detrimento das partes. Fazendo uma análise dos sistemas processuais penais, Jacinto Nelson de Miranda Coutinho lembra que um devido processo legal (constitucional) é incompatível com o sistema inquisitorial no qual existe extrema concentração dos poderes nas mãos do julgador. O processo constitucional se coaduna com o sistema acusatório, uma vez que não concebe a existência de hierarquia entre as partes e o juiz (NELSON, Jacinto. A contribuição da Constituição democrática ao processo penal inquisitório brasileiro. In: MACHADO, Felipe Daniel Amorim; CATTONI DE OLIVEIRA, Marcelo Andrade (Coord.). Constituição e processo: a contribuição do processo ao constitucionalismo brasileiro. Belo Horizonte: Del Rey, 2009. p. 221-231, p. 18-20.

69 BRÊTAS, Ronaldo de Carvalho Dias, op. cit., p. 467.

70 BARACHO, José Alfredo de Oliveira, 1997, p. 119.

71 Ibidem, p. 108.

72 LEAL, Rosemiro Pereira, op. cit., p. 104.

73 NUNES, Dierle José Coelho, op. cit., p. 197.

74 Ibidem, p. 200.

75 GONÇALVES, Aroldo Plínio, op. cit., p. 120-121.

76 NUNES, Dierle José Coelho, op. cit., p. 200.

77 “O juiz que não se conforma com uma atuação meramente burocrática e que repensa continuamente os aspectos institucionais de seu mister não se acomoda perante esse quadro. Procura contribuir para a reflexão que não é só dele, mas de todos os interessados na preservação da democracia, alternativa menos falível de uma vida social digna e da qual o 
juiz é categorizado avalista" (NALINI, José Renato. O juiz e o acesso à justiça. São Paulo: Revista dos Tribunais, 1994. p. 10).

78 LEAL, Rosemiro Pereira, op. cit., p. 54.

79 Idem, p. 63.

80 ROSA, Alexandre de Morais da. Decisão penal: a bricolage de significantes. Rio de Janeiro: Lumnen Juris, 2006. p. 266.

81 Nesse sentido, válida a crítica de Ronaldo Brêtas de Carvalho Dias: “Obviamente, quando os órgãos jurisdicionais descumprem essas normas do ordenamento jurídico, o que é prática ilícita corriqueira no Estado brasileiro, a jurisdição se apresenta como morosa, intempestiva e ineficiente, ao contrário do que se fala - 'processo moroso' - de forma tecnicamente inadequada. Na realidade, não é o processo que se mostra moroso, mas morosa é a atividade essencial monopolizada pelo Estado, denominada jurisdição, até porque, normalmente, as partes cumprem os prazos que lhe são impostos, a fim de lhes afastar a inexorável preclusão temporal, que é a perda do direito à prática do ato processual pelo decurso do prazo. Os órgãos jurisdicionais do Estado brasileiro é que sistemática e ilicitamente não cumprem os prazos que o ordenamento jurídico lhes determina para a prática dos atos jurisdicionais nos processos, sem que nada aconteça aos agentes públicos julgadores infratores" (BRÊTAS, Ronaldo de Carvalho Dias. Fundamentos constitucionais da jurisdição no Estado Democrático de Direito. In: GALUPPO, Marcelo Campos (Coord.). Constituição e democracia: fundamentos. Belo Horizonte: Fórum, 2009. p. 304.)

82 SOARES, Carlos Henrique. O Advogado e o processo constitucional. Belo Horizonte: Decálogo, 2004. p.72.

83 THEODORO JÚNIOR, Humberto, 2003, v. 1, p. 24. CINTRA, Antônio Carlos de Araújo; GRINOVER, Ada Pellegrini; DINAMARCO, Cândido Rangel, 1999, p. 57. SANTOS, Ernane Fidélis dos. Manual de direito processual civil. São Paulo: Saraiva, 1996. v. 1, p. 36.

84 LEAL, Rosemiro Pereira, 2010, p. 97.

85 BARROS, Flaviane de Magalhães, 2009, p. 19

86 STRECK, Lênio Luiz. Hermenêutica, constituição e processo, ou de "como discricionariedade não combina com democracia"; o contraponto da resposta correta, 2009, p. 19. NUNES, Dierle José Coelho, 2010, p. 227. BARROS, Flaviane de Magalhães, 2009, p. 18.

87 BARROS, Flaviane de Magalhães, 2009, p. 18.

88 Nesse sentido, v.g., decidiu o Tribunal de Justiça do Estado de Minas Gerais: “O julgador, ao decidir, não está obrigado a se manifestar expressamente sobre todos os pontos que a parte entender relevantes, podendo fazê-lo implicitamente" (TJMG, Apelação Criminal $\mathrm{n}^{\circ}$ 1.0024.08.074418-8/001(1), rel. desembargador Antônio Carlos Cruvinel, 30-07-2009). Por sua vez, o Superior Tribunal de Justiça: “A jurisprudência desta Corte já consagrou a orientação de não ser carente de fundamentação o decisum que, cotejando as provas contidas nos autos, faz menção direta às razões que serviram para afastar, expressamente, as teses da defesa e formar a convicção do Magistrado, sendo desnecessária a menção exaustiva de cada uma das hipóteses defensivas que não foram acolhidas" (STJ, HC nº 136.659/SC, $5^{\text {a }}$ Turma, rel. min. Napoleão Nunes Maia Filho, DJe 3-5-2010). E, ao arremate, o Supremo Tribunal Federal decidiu que "[...] o órgão judicante não é obrigado a se manifestar sobre todas as teses apresentadas pela defesa, bastando que aponte fundamentadamente as razões de seu convencimento" (AI no 690.504-AgR, rel. min. Joaquim Barbosa, DJE, 23-5-2008).

89 “E M E N T A: HABEAS CORPUS - ACÓRDÃOS PROFERIDOS EM SEDE DE APELAÇÃO E DE EMBARGOS DECLARATÓRIOS - IMPUTAÇÃO DE ROUBO DUPLAMENTE QUALIFICADO - DECISÕES QUE NÃO ANALISARAM OS ARGUMENTOS SUSCITADOS PELA DEFESA DO RÉU - EXIGÊNCIA CONSTITUCIONAL DE MOTIVAÇÃO DOS ATOS DECISÓRIOS - INOBSERVÂNCIA - NULIDADE DO ACÓRDÃO-PEDIDO DEFERIDO EM PARTE. A FUNDAMENTAÇÃO CONSTITUI PRESSUPOSTO DE LEGITIMIDADE DAS DECISÕES JUDICIAIS. A fundamentação dos atos decisórios qualifica-se como pressuposto constitucional de validade e eficácia das decisões emanadas do Poder Judiciário. A inobservância do dever imposto pelo art. 93, IX, da Carta Política, precisamente por traduzir grave transgressão de natureza constitucional, afeta a legitimidade jurídica do ato decisório e gera, de maneira irremissível, a consequente nulidade do pronunciamento judicial. Precedentes. 
A DECISÃO JUDICIAL DEVE ANALISAR TODAS AS QUESTÕES SUSCITADAS PELA DEFESA DO RÉU. Reveste-se de nulidade o ato decisório, que, descumprindo o mandamento constitucional que impõe a qualquer Juiz ou Tribunal o dever de motivar a sentença ou o acórdão, deixa de examinar, com sensível prejuízo para o réu, fundamento relevante em que se apoia a defesa técnica do acusado" (Habeas Corpus n ${ }^{\circ} 74.073$, rel. min. Celso de Mello, j. 20-05-1997, p. DJ 27-06-1997 PP-30227, EMENT VOL-01875-03 PP-00597).

90 LEAL, André Cordeiro. O contraditório e a fundamentação das decisões jurisdicionais no direito processual democrático. Belo Horizonte: Mandamentos, 2002. p. 77.

91 FERRAJOLI, Luigi. Direito e razão: teoria do garantismo penal. 2. ed. São Paulo: Revista dos Tribunais, 2006. p. 519-520.

92 CORDEIRO, Franco. Procedimiento penal. Santa Fé de Bogotá: Temis, 2000. p. 21.

93 COUTINHO, Jacinto Nelson de Miranda. A contribuição da constituição democrática ao processo penal inquisitório brasileiro. In: MACHADO, Felipe Daniel Amorim; CATTONI DE OLIVEIRA, Marcelo Andrade (Coord.). Constituição e processo: a contribuição do processo ao constitucionalismo democrático brasileiro. Belo Horizonte: Del Rey, 2009. p. 224.

94 É o que se extrai do texto do art. 156 do Código de Processo Penal, em que pese a duvidosa constitucionalidade do dispositivo. Nesse sentido: "A gestão da prova pelo julgador, de ofício, conforme a nova redação do artigo 156, I e II, do CPP, torna ilegítimo o processo penal, fere o contraditório, a Constituição da República e consolida o risco (concreto) de opções arbitrárias, além de permitir a fusão, em um círculo concêntrico, da ação e jurisdição, elementos estanques e distintos" (CARVALHO, Luís Gustavo Grandinetti Castanho de; DEPAOLI, Solon Bittencourt. Por que o juiz não deve produzir provas: a nova redação do art. 156 do $\mathrm{CPP}\left(\right.$ Lei n $\left.^{\circ} 11.690 / 2008\right)$. Boletim do Instituto Brasileiro de Ciências Criminais (IBBCRIM), ano 16, n. 190, p. 6-7, set. 2008).

95 Conforme dispõe o Código de Processo Penal em seu art. 386, II, III, V e VII.

96 ROSA, Alexandre de Morais da. Decisão penal: a bricolage de significantes. Rio de Janeiro: Lumen Juris, 2006. p. 264.

97 A Constituição não faz referência à presunção de inocência, mas presunção de não culpabilidade (art. 5, LVII). Tratando-se, porém, de presunção relativa, uma vez que cede diante da prova em contrário reconhecida pela sentença penal condenatória.

98 PLETSH, Natalie Ribeiro. Formação da prova no jogo processual penal: o atuar das partes e a construção da sentença. São Paulo: IBCCRIM, 2007. p. 79.

99 CARVALHO, Luís Gustavo Grandinetti Castanho de; DEPAOLI, Solon Bittencourt, op. cit.

100 No tocante à imparcialidade do juiz, importante salientar com Alexandre de Morais da Rosa: “Advirta-se, por fim, que a atuação do juiz, no procedimento, não pode ser a de realizar os anseios sociais, devendo se postar de maneira imparcial, garantindo o equilíbrio do contraditório, ou seja, a verdadeira democracia processual. Todavia, o ato decisório, a pretensão habermasiana não pode ser acolhida como se mostra (cap. 3). Evidente que os argumentos formulados pelas partes devem ser levados em consideração no momento da decisão, fundamentando-se as pretensões de validade, mas não se pode negar pela construção até aqui realizada, que o um-julgador esteja informado por fatores externos, condicionantes ideológicos, criminológicos, midiáticos, inconscientes, enfim, subjetivos que sempre são co-produtores da decisão, mesmo que obliterados retoricamente" (ROSA, Alexandre de Morais da. 2006, p. 266.)

101 BARROS, Flaviane de Magalhães, 2009, p. 19.

102 LEAL, Rosemiro Pereira, 2010, p. 96-97.

103 LOPES JÚNIOR. Aury. Direito processual penal e sua conformidade constitucional. 5. ed. Rio de Janeiro: Lumnen Juris, 2010. p. 116.

104 Contraditório, ampla defesa (ou ampla argumentação) e isonomia constituem os princípios institutivos do processo. Sem qualquer um deles, o processo se desnatura em mero procedimento. (LEAL, Rosemiro Pereira, 2010, p. 96)

105 STRECK, Lênio Luiz, 2009, p. 18.

106 Conforme Constituição da República Federativa do Brasil, art. 93, IX.

107 BARROS, Flaviane de Magalhães, op. cit., p. 19. BRÊTAS, Ronaldo de Carvalho Dias, 2004, p. 277-309. 


\section{REFERÊNCIAS}

ALEXY, Robert. Teoria dos direitos fundamentais. Tradução de Virgílio Afonso da Silva. São Paulo: Malheiros, 2008.

ALVIM, José Eduardo Carreira. Teoria geral do processo. 8. ed. Rio de Janeiro: Forense, 2002.

ANDOLINA, Italo. O papel do processo na atuação do ordenamento constitucional e transnacional. Revista de Processo, São Paulo, v. 87, p. 63-69, jul./set. 1997.

ARAÚJO, Marcelo Cunha de. O novo processo constitucional. Belo Horizonte: Mandamentos, 2003.

ÁVILA, Humberto. Teoria dos princípios. 10. ed. ampl. e atual. São Paulo: Malheiros, 2009.

BARACHO, José Alfredo de Oliveira. Processo constitucional. Rio de Janeiro: Forense, 1984.

BARACHO, José Alfredo de Oliveira. Processo constitucional. Revista Forense, Rio de Janeiro, v. 337, p. 105-123, jan./mar. 1997.

BARACHO, José Alfredo de Oliveira. Teoria geral do processo constitucional. Revista da Faculdade Mineira de Direito, Belo Horizonte, v. 2 , n. 3 e 4 , p. $89-154,1^{\circ}$ e $2^{\circ}$ sem. 1999.

BARACHO, José Alfredo de Oliveira. Processo constitucional: aspectos contemporâneos. Belo Horizonte: Fórum, 2008.

BARROS, Flaviane de Magalhães. (Re)forma do processo penal. 2. ed. Belo Horizonte: Del Rey, 2009.

BARROS, Flaviane de Magalhães. O modelo constitucional de processo e o processo penal: a necessidade de uma interpretação das reformas do processo penal a partir da Constituição. In: MACHADO, Felipe Daniel Amorim; CATTONI DE OLIVEIRA, Marcelo Andrade (Coord.). Con- 
stituição e processo: a contribuição do processo ao constitucionalismo brasileiro. Belo Horizonte: Del Rey, 2009. p. 331-345.

BARROSO, Luís Roberto. Interpretação e aplicação da Constituição. 7. ed. rev. São Paulo: Saraiva, 2009.

BONAVIDES, Paulo. Do Estado Liberal ao Estado Social. 3. ed. Belo Horizonte: Del Rey, 1993.

BONAVIDES, Paulo. A Constituição aberta: temas políticos e constitucionais da atualidade. Belo Horizonte: Del Rey, 1993.

BONAVIDES, Paulo. Curso de direito constitucional. 11. ed. São Paulo: Malheiros, 2001.

BRÊTAS, Ronaldo de Carvalho Dias. Fraude no processo civil. 3. ed. Belo Horizonte: Del Rey, 2001.

BRÊTAS, Ronaldo de Carvalho Dias. Uma introdução ao estudo do direito político. Revista do Instituto dos Advogados de Minas Gerais, Belo Horizonte, v. 8, p.107-122, 2002.

BRÊTAS, Ronaldo de Carvalho Dias. Responsabilidade do Estado pela função jurisdicional. Belo Horizonte: Del Rey, 2004.

BRÊTAS, Ronaldo de Carvalho Dias. Fundamentos do Estado Democrático de Direito. Revista da Faculdade Mineira de Direito, Belo Horizonte, v. 7, n. 13 e 14, p. 150-163, $1^{\circ}$ e $2^{\circ}$ sem./ 2004.

BRÊTAS, Ronaldo de Carvalho Dias. A garantia da fundamentação das decisões jurisdicionais no Estado Democrático de Direito. Revista da Faculdade Mineira de Direito, Belo Horizonte, v. 8, n. 16, p. 147-161, $2^{\circ} \mathrm{sem} / 2005$.

BÊTAS, Ronaldo de Carvalho Dias. Direito à jurisdição eficiente e garantia da razoável duração do processo no Estado Democrático de Direito. In: GALUPPO, Marcelo Campos (Org.). O Brasil que quere- 
mos: reflexões sobre o Estado Democrático de Direito. Belo Horizonte: Editora Puc/Minas, 2006. p. 653-663.

BRÊTAS, Ronaldo de Carvalho Dias. Exame técnico e sistemático do Código de Processo Civil reformado. In: BRÊTAS, Ronaldo de Carvalho Dias; DINIZ NEPOMUCENO, Luciana (Coord.). Processo civil reformado. Belo Horizonte: Del Rey, 2009. p. 407-456.

BRÊTAS, Ronaldo de Carvalho Dias. As reformas do Código de Processo Civil e o processo constitucional. In: BRÊTAS, Ronaldo de Carvalho Dias; DINIZ NEPOMUCENO, Luciana (Coords.). Processo civil reformado. Belo Horizonte: Del Rey, 2009. p. 457-496.

BRÊTAS, Ronaldo de Carvalho Dias. Fundamentos constitucionais da jurisdição no Estado Democrático de Direito. In: GALUPPO, Marcelo Campos (Coord.). Constituição e democracia: fundamentos. Belo Horizonte: Fórum, 2009. p. 227-309.

CALAMANDREI, Piero. Instituciones de derecho procesal civil. Buenos Aires: Ediciones Juridicas Europa-America (E.J.E.A), 1962. v. 1.

CÂMARA, Alexandre Freitas. Lições de direito processual civil. 11. ed. Rio de Janeiro: Lumen Juris, 2004.

CANOTILHO, José Joaquim Gomes. Direito constitucional e teoria da constituição. 5. ed. Coimbra: Almedina, 2002.

CARNELUTTI, Francesco. Instituiciones del proceso civil. Buenos Aires: Ediciones Juridicas Europa-America (E.J.E.A), 1959. v. 1.

CARVALHO, Luís Gustavo Grandinetti Castanho de; DEPAOLI, Solon Bittencourt. Por que o juiz não deve produzir provas: a nova redação do art. 156 do CPP (Lei ${ }^{\circ}$ 11.690/2008). Boletim do Instituto Brasileiro de Ciências Criminais (IBBCRIM), ano 16, n. 190, p. 6-7, set. 2008.

CARVALHO NETO, Menelick. A hermenêutica constitucional sob o paradigma do Estado Democrático de Direito. In: OLIVEIRA, Marcelo 
Andrade Cattoni de (Coord.). Jurisdição e hermenêutica constitucional. Belo Horizonte: Mandamentos, 2004. p. 25-44.

CASTRO, Carlos Roberto de Siqueira. O devido processo legal e a razoabilidade das leis na nova Constituição do Brasil. 2. ed. Rio de Janeiro: Forense, 1989.

CATTONI DE OLIVEIRA, Marcelo Andrade. O processo constitucional como instrumento da jurisdição constitucional. Revista da Faculdade Mineira de Direito, Belo Horizonte, v. 3, n. 5 e 6, p. $161-169,1^{\circ}$ e $2^{\circ}$ sem./2000.

CATTONI DE OLIVEIRA, Marcelo Andrade. A legitimidade democrática da Constituição da República Federativa do Brasil: uma reflexão sobre o projeto constituinte do Estado Democrático de Direito no marco da teoria do discurso de Jüngen Habermas. In: GALUPPO, Marcelo Campos (Coord.). Constituição e democracia: fundamentos. Belo Horizonte: Fórum, 2009. p. 235-262.

CINTRA, Antônio Carlos de Araújo; GRINOVER, Ada Pellegrini; DINAMARCO, Cândido Rangel. Teoria geral do processo. 15. ed. São Paulo: Malheiros, 1999.

CORDEIRO, Franco. Procedimiento penal. Santa Fé de Bogotá: Temis, 2000 .

CRUZ, Álvaro Ricardo de Souza. Jurisdição constitucional democrática. Belo Horizonte: Del Rey, 2004.

DEL NEGRI, André. Controle de constitucionalidade no processo legislativo: teoria da legitimidade democrática. 2. ed. Belo Horizonte: Fórum, 2008.

FAZZALARI, Elio. Instituições de direito processual. Campinas: Bookseller, 2006.

FERRAJOLI, Luigi. Direito e razão: teoria do garantismo penal. 2. ed. São Paulo: Revista dos Tribunais, 2006. 
GARAPON. Antonie. O juiz e a democracia: o guardião das promessas. 2. ed. Rio de Janeiro: Revan, 2001.

GONÇALVES, Aroldo Plínio. Técnica processual e teoria do processo. Rio de Janeiro: Aide, 1992.

GONÇALVES, Aroldo Plínio. Nulidades no processo. Rio de Janeiro: Aide, 2000.

HABERMAS, Jürgen. Direito e democracia: entre facticidade e validade. Rio de Janeiro: Tempo Universitário, 1997. v. II.

LARA, Leonardo Augusto Leão; CARVALHO, Newton Teixeira de; PENNA, Saulo Versiani. Processo, ação e jurisdição em Fazzalari. In: LEAL, Rosemiro Pereira. Estudos continuados de processo, São Paulo: IOB Thonsom, 2004. v. V.

LEAL, André Cordeiro. O contraditório e a fundamentação das decisões jurisdicionais no direito processual democrático. Belo Horizonte: Mandamentos, 2002.

LEAL, André Cordeiro. Instrumentalidade do processo em crise. Belo Horizonte: Mandamentos, 2008.

LEAL, Rosemiro Pereira. Teoria processual da decisão jurídica. São Paulo: Landy, 2002.

LEAL, Rosemiro Pereira. Modelos processuais e constituição democrática. In: MACHADO, Felipe Daniel Amorim; CATTONI DE OLIVEIRA, Marcelo (Coord.). Constituição e processo: a contribuição do processo ao constitucionalismo brasileiro. Belo Horizonte: Del Rey, 2009.

LEAL, Rosemiro Pereira. Teoria geral do processo: primeiros estudos. 9. ed. Rio de Janeiro: Forense, 2010.

LOPES JR. Aury. Direito processual penal e sua conformidade constitucional. 5. ed. Rio de Janeiro: Lumnen Juris, 2010. 
MENDES, Gilmar Ferreira; MÁRTIRES COELHO, Inocêncio; GONET BRANCO, Paulo Gustavo. Curso de direito constitucional. 4. ed. São Paulo: Saraiva, 2009.

NALINI, José Renato. O juiz e o acesso à justiça. São Paulo: Revista dos Tribunais, 1994.

NELSON, Jacinto. A contribuição da Constituição democrática ao processo penal inquisitório brasileiro. In: MACHADO, Felipe Daniel Amorim; CATTONI DE OLIVEIRA, Marcelo Andrade (Coord.). Constituição e processo: a contribuição do processo ao constitucionalismo brasileiro. Belo Horizonte: Del Rey, 2009. p. 221-231.

NUNES, Dierle José Coelho. Processo jurisdicional democrático. Curitiba: Juruá Editora, 2010.

PLETSH, Natalie Ribeiro. Formação da prova no jogo processual penal: o atuar das partes e a construção da sentença. São Paulo: IBCCRIM, 2007.

ROSA, Alexandre de Morais da. Decisão penal: a bricolage de significantes. Rio de Janeiro: Lumnen Juris, 2006.

SANTOS, Ernane Fidélis dos. Manual de direito processual civil. São Paulo: Saraiva, 1996. v. I.

SARMENTO, Daniel. Os direitos fundamentais nos paradigmas liberal, social e pós-social (pós-modernidade constitucional?). In: SAMPAIO, José Adércio Leite (Coord.). Crise e desafios da Constituição. Belo Horizonte: Del Rey, 2004. cap. 18, p. 375-414.

SILVA FILHO, Alberico Alves da. Jurisdição constitucional e judicação na teoria do direito democrático. In: LEAL, Rosemiro Pereira (Coord.). Estudos continuados de teoria do processo. Porto Alegre: Síntese, 2000. v. III, p. 127-179.

SOARES, Carlos Henrique. O advogado e o processo constitucional. Belo Horizonte: Decálogo, 2004. 
SOARES, Mário Lúcio Quintão. Teoria do Estado. Belo Horizonte: Del Rey, 2001.

STRECK, Lênio Luiz. Hermenêutica, Constituição e processo, ou "como discricionariedade não combina com democracia"; o contraponto da resposta correta. In: MACHADO, Felipe Daniel Amorim; CATTONI DE OLIVEIRA, Marcelo Andrade (Coord.). Constituição e processo: a contribuição do processo ao constitucionalismo brasileiro. Belo Horizonte: Del Rey, 2009. p. 3-27.

THEODORO JÚNIOR, Humberto. Curso de direito processual civil. 39. ed. Rio de Janeiro: Forense, 2003. v. I.

VARGAS, José Cirilo de. Processo penal e direitos fundamentais. Belo Horizonte: Del Rey, 1992.

Artigo recebido em: 12-9-2012

Aprovado em: 18-12-2013

\section{Fábio Passos Presoti}

Doutorando em Direito Processual pela Pontifícia Universidade Católica de Minas Gerais (PUC-MG); mestre em Direito Processual pela Pontifícia Universidade Católica de Minas Gerais (PUC-MG); especialista em Ciências Penais pela Pontifícia Universidade Católica de Minas Gerais (PUC-MG); professor da Faculdade Minas Gerais (FAMIG).

Faculdade Minas Gerais (FAMIG) Avenida do Contorno, 10.185. Prado CEP 30110-067. Belo Horizonte - MG. E-mail: fabiopresoti@yahoo.com.br
José de Assis Santiago Neto

Mestre em Processo pela Pontifícia Universidade Católica de Minas Gerais (PUC-MG); especialista em Ciências Penais pela Pontifícia Universidade Católica de Minas Gerais (PUC_MG); professor assistente da Pontifícia Universidade Católica de Minas Gerais (PUC/MG) no campus Betim; membro da Diretoria do Instituto de Ciências Penais.

Santiago e Associados Advocacia Avenida Francisco Sá, no 1213, $10^{\circ}$ Andar. Gutierrez. CEP 30430-030 Belo Horizonte - MG.

E-mail: jose.santiago@santiago associados.com.br 